\title{
Research on Car Crashworthiness in Car-to-Truck Offset Rear-end Collisions
}

\author{
Pengfei $\mathrm{Cao}^{1, \mathrm{a}^{*}, \mathrm{Na} \mathrm{Yang}^{1} \text { and Xiaoling Sun }}{ }^{1}$ \\ ${ }^{1}$ School of Automotive Engineering, Harbin Institute of Technology at Weihai, 264209, China \\ acaopf19901116@163.com
}

Keywords: Crashworthiness, Offset Impact, Rear-end Collisions.

Abstract. The safety of the vehicle occupants in car-to-truck rear-end collisions is directly related to the crashworthiness of the car body. This paper mainly studied the effect of sensitive parameter named offset rate on car structural crashworthiness in rear-end accident. In order to provide a reference on the promotion of car crashworthiness and improvement of truck's underride guard, this paper analyzed the load path and deformation process of rear-end collisions by simulation method, and mainly focused on the changes of car acceleration, intrusion volume and invasive procedure under different offset rate.

\section{Introduction}

With the development of the automotive safety regulations, foreign scholars in crash safety direction conducted lots of real vehicle tests and simulation studies. Ajit D Kekar, Mark J Schulz et al., as well as NK Saha, SM Calso et al., researched on vehicle frontal collisions form and simulated frontal crash tests under different offset rate, and analyzed the intrusion volume, deceleration and other indicators of crashworthiness $^{[1,2]}$. In rear-end vehicle collisions filed, foreign researchers mainly study the effects of occupant's body injury in the whiplash test from the perspective of occupant passive safety ${ }^{[3]}$. Foreign countries also noticed the rear-end collisions from truck accident, such as, Atahan Ali O, et al. took the car-to-heavy vehicle rear-end accident into account, and designed a special underride guard ${ }^{[4]}$. Jikuang Yang optimized the crashworthiness design based on the fuel leak problem in rear-end vehicle collisions $^{[5]}$. By tests and simulation research on passenger car-to-truck rear-end accident Zhonghao Bai, Libo Cao et al. pointed out the existing shortcomings of the protective equipment regulations ${ }^{[6]}$. In response to this situation, the paper simulated car-to-truck rear-end tests under different offset rate, and studied car crash safety in that case.

\section{The effects of different offset rate on car crashworthiness}

The offset collisions is common in car-to-truck rear-end accident. This section studied the car-to-truck offset rear-end crash through simulation approach. 80\%, 70\%, 60\%, 50\%, 40\% and 30\% totally six kinds of offset rate would be set up in this paper via referring to foreign experience, and the impact speed is set at $56 \mathrm{~km} / \mathrm{h}$. From the results of foreign offset crash test, truck underrun protection capacity decreased in offset condition, and car A-pillar is prone to be invaded. Thus the main assessment goals of this section include peak acceleration of car lower B-pillar, the depth of underride, car A-pillar intrusion situation.

\subsection{Car deformation process of offset collisions}

The paper got collisions process under different offset rate. Represented by $50 \%$ offset rate crash, the concrete collisions process is shown in Fig. 1. As could be seen from the timing diagram, when car got offset rear-ended, the truck's underride guard bear uneven force then lost effectiveness and failed to stop the car moving continuously. The component at the front of car also failed to play a full role of energy absorption, causing the car left A-pillar to be invaded directly, which made cab become deformed severely. What's more, the rotational motion of the car during impact process aggravated the intrusion of cab. Meanwhile, the left door became severely deformed, affecting its opening and closing. In offset collisions accident, the spacing of truck's underride guard cantilever is an important structure 
parameter affecting the rear protective stiffness. This article suggests increasing the spacing of truck's underride guard cantilever to improve truck underrun protection capability in offset collisions.
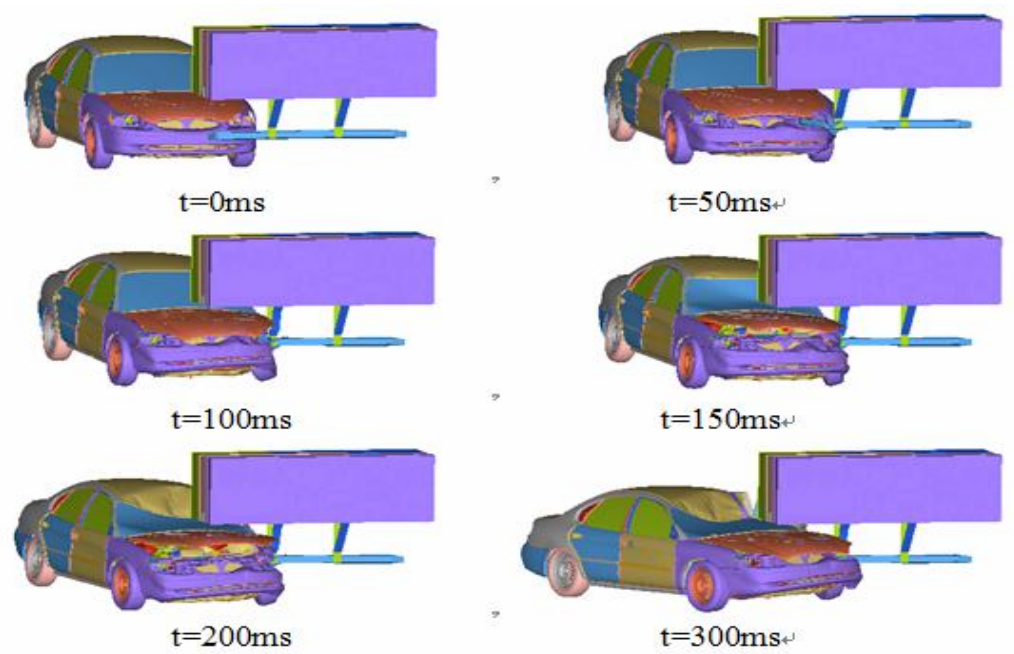

$\mathrm{t}=150 \mathrm{~ms}$

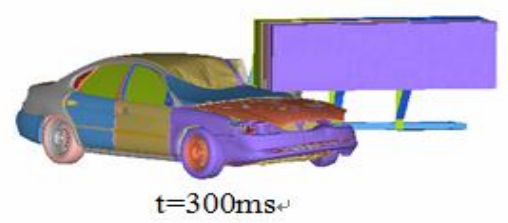

Fig. 1 Timing diagram of $50 \%$ offset rate collisions

\subsection{Crash simulation results under different offset rate}

Fig. 2 is the ultimate form of different offset rate after the collisions. The main assessment goals of this section include peak acceleration of car lower B-pillar, the depth of underride and the car A-pillar intrusion situation.
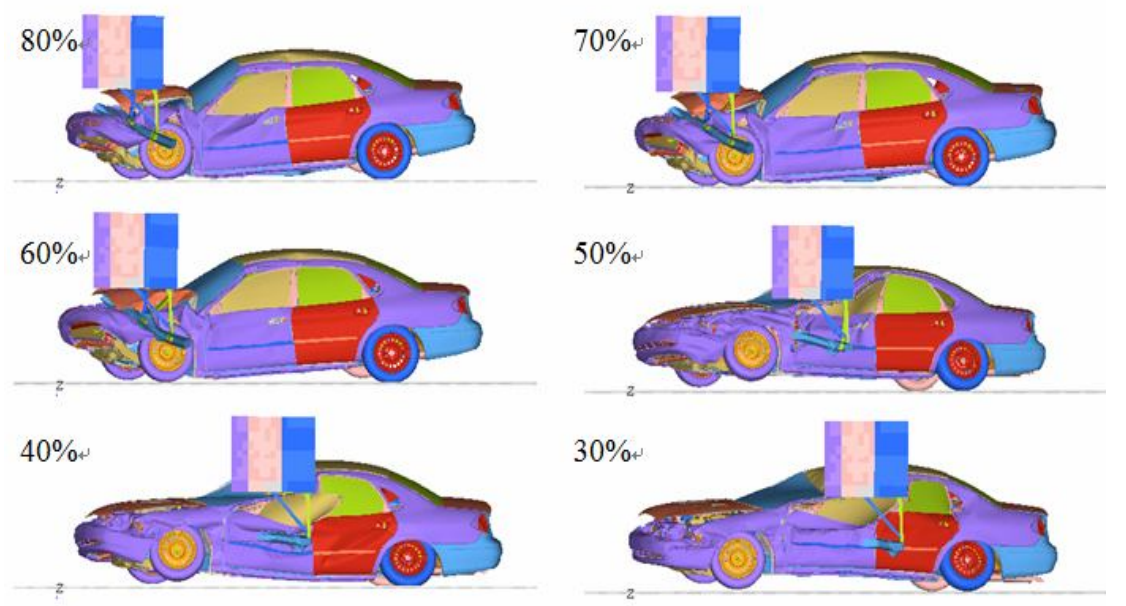

Fig. 2 The ultimate collisions form of different offset rate

\subsubsection{The peak acceleration of car lower B-pillar}

According to the simulation results, truck's underride guard could prevent the car from moving under $80 \%, 70 \%$ and $60 \%$ offset rate successfully. While truck's underride guard would be failed and car cab underwent significant intrusion under 50\%, 40\%, 30\% offset rate. Peak acceleration of lower B-pillar will rise sharply for the car rear-end accidents under less than $50 \%$ offset rate, far more than the large offset rate and even reaching more than $80 \mathrm{~g}$. Furthermore, the car cab would suffer severe deformation after the failure of underride guard. So the noise coming from serious invasion of the cab will lead to significant oscillation of acceleration waveform and it could be difficult to handle by simple filtering. Therefore, the paper only listed lower B-pillar acceleration curve under $80 \%, 70 \%, 60 \%$ offset rate, as shown in Fig. 3.

Curves are shown that the peak acceleration of lower B-pillar under offset collisions is higher than that of $100 \%$ rear-end situation. Along with reducing the offset rate, the acceleration of lower B-pillar tended to increase, but the extent of increase was not significant. This is because, with the decrease of the offset rate, the block capacity of truck's underride guard diminished. Meanwhile, Along with the 
trend of the rotational movement of the car increased, the acceleration of lower B-pillar generated component, resulting in no significant change in acceleration amplitude.

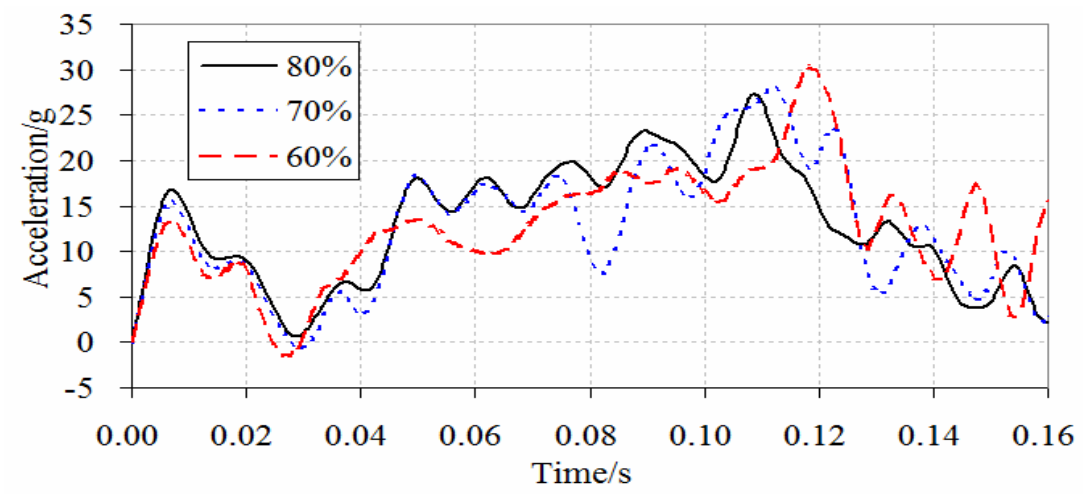

Fig. 3 The acceleration curves of car lower B-pillar under $80 \% 、 70 \% 、 60 \%$ offset rate

\subsubsection{The depth of car underride}

The depth of car underride is the most important characteristic for truck's underride guard's protection capability. The curve Fig. 4 shows that the depth of car underride displays an upward trend with the decreasing of offset rate, which could clearly be seen that the $50 \%$ offset rate is a watershed. The depth of car underride is less than $1000 \mathrm{~mm}$ while the offset rate is greater than $50 \%$, and the depth of car underride is far more than $1000 \mathrm{~mm}$ while the offset rate is less than $50 \%$. What's more, the depth of car underride expresses even more than $3000 \mathrm{~mm}$ under $30 \%$ offset rate. The front length of China's car are no more than $1 \mathrm{~m}$ generally, which means that the truck's underride guard could ensure the vehicle occupants' safety through its blocking effect when the offset rate is more than $50 \%$. While the offset rate is lower than $50 \%$, the car cab would be seriously invaded. Therefore, to reduce underride deaths and injuries, the inspection standards of truck's underride guard should be improved and the crash tests should be conducted in offset conditions. Meanwhile, the crashworthiness of car body should also be enhanced purposefully.

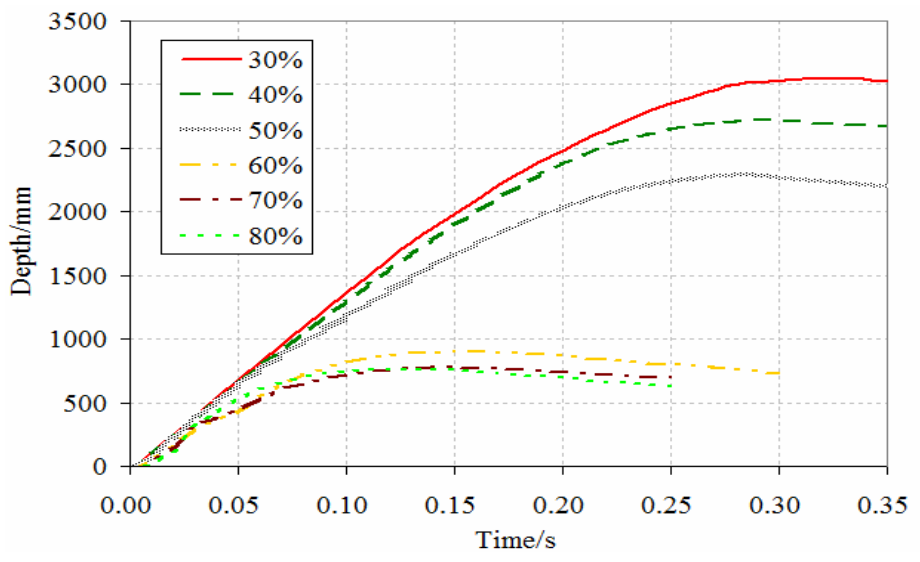

Fig. 4 The depth of car underride under different offset rate

\subsubsection{Deformation of car A-pillar}

According to collisions deformation under different offset rate, this article selected car A-pillar bending angle under $80 \%, 70 \%, 60 \%$ offset rate and A-pillar intrusion volume under $50 \%, 40 \%$ offset rate to analysis. Based on this fact that car A-pillar would be completely invaded under small offset rate, there is no longer represented by curves.

Fig. 5 and Fig. 6 shows that car A-pillar bending angle tends to increase with the decrease of offset rate in $80 \%, 70 \%$ and $60 \%$ cases. We also find that car A-pillar bending angle do not change significantly when the offset rate changes from $80 \%$ to $70 \%$. But it improves significantly when the offset rate changes from $70 \%$ to $60 \%$. This phenomenon shows that the influence of the offset rate to 
car crashworthiness is not a simple linear relationship. Combined with the variation of the underride depth, it found offset rate range between $50 \%$ and $60 \%$ has a major change in car crashworthiness. So the offset rate could be set within the range in carrying out underride crash test. In addition, the results also show A-pillar intrusion volume in $40 \%$ case is more than $50 \%$ case, and the intrusion velocity is also higher than $50 \%$ case. While the A-pillar has been completely invaded in $30 \%$ case, it shows that, after the failure of the truck protective device, the lower of offset rate the more demanding for the crashworthiness of the A-pillar. Considering the offset underride crash in real traffic accident, the structure crashworthiness of the A-pillar should be strengthened reasonably.

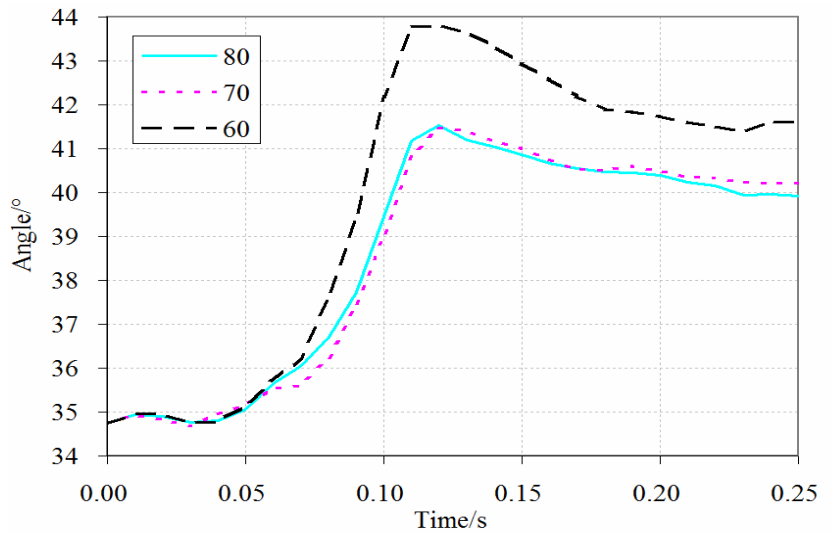

Fig. 5 A-pillar bending angle

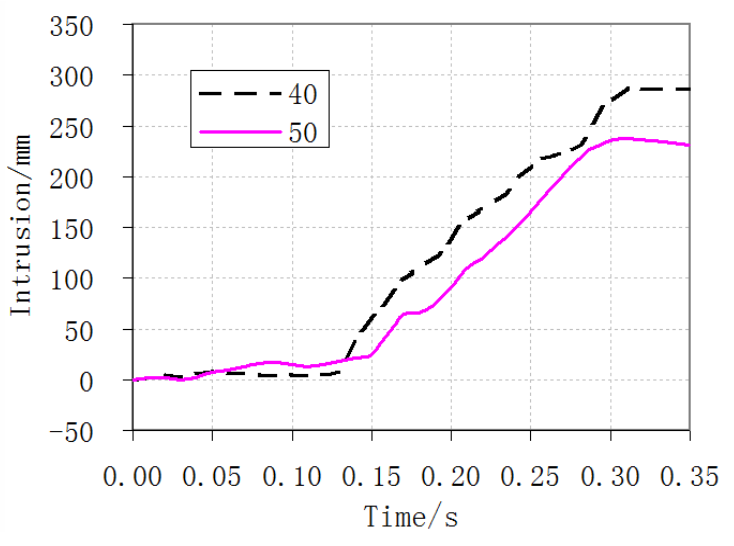

Fig. 6 A-pillar intrusion volume

\section{Summary}

Studied on offset underride crash, this paper simulated and analyzed crashworthiness indicators under different offset rate. The results show that underride could easily occur in car-to-truck rear-end accident, and offset rate affects car crashworthiness significantly. According to the research the spacing of truck's underride guard cantilever should be improved, and offset collisions form should be considered in its crash evaluation system. Meanwhile, crashworthiness of car body should be improved purposely in car rear-end accident.

\section{References}

[1] N K Saha, S M Calso, et a1.Simulation of Frontal Barrier Offset Impacts and Comparison of Intrusions and Decelerations[R]. SAE 950647, 1995.

[2] Ajit D Kekar, Mark J Schulz, et a1. Simulation of a Car Frontal Offset Impact into a Fixed Deformable Barrier[R]. SAE 962485, 1996.

[3] Mansour Rami, Romilly Douglas. Application of energy-absorbing foam to the seat base to mitigate whiplash injuries in rear end collisionss[R]. SAE Technical Papers, 2011.

[4] Atahan Ali O, Joshi Abhishek S, El-Gindy Moustafa. A rear-end protection device for heavy vehicles[J]. American Society of Mechanical Engineers(ASME), 2003: 47-55.

[5] YANG J K, TANG C Q. Structural Crashworthiness Optimization Design in High Speed Car Rear-end Collisions[J]. Chinese Mechanical Engineering, 2011, 22(5): 616-620.

[6] BAI Z H, MA W J, CAO L B, ZHANG Q B. Study on Car-to-Truck Rear-end Impact Experiment and Simulation Base on Accident Analysis[J].Chinese Mechanical Engineering, 2011, 21(14): 1742-1747. 